\title{
A Economia Falibilista de Hayek
}

\section{Fabio Barbieri*}

Resumo: Este artigo busca apresentar as ideias de Hayek a partir da identificação de um tema unificador, presente em diversas de suas teorias. O sistema explanatório do autor trata da liberdade como parte de um mecanismo descentralizado de aprendizado capaz de contornar as limitações do conhecimento humano necessário para coordenar as ações em sistemas progressivamente mais complexos. $\mathrm{O}$ artigo trata de diversos problemas interpretativos a partir da perspectiva que enfatiza a centralidade do conhecimento falível e de estruturas complexas em sua obra.

Palavras-Chave: F. A. Hayek, Falibilismo, Coordenação, Liberdade.

\section{Hayek's Fallibilist Economics}

\begin{abstract}
This article seeks to present Hayek's ideas from the identification of a unifying theme, present in many of his theories. His explanatory system addresses liberty as part of a decentralized learning mechanism capable of circumvent the limitations of the knowledge necessary to coordinate actions in progressively more complex environments. The article deals with various interpretative issues from the perspective that emphasizes the centrality of fallible knowledge and complex structures in his work.
\end{abstract}

Keywords: F. A. Hayek, Falibilism, Coordination, Liberty.

Classificação JEL: B31, B25

\footnotetext{
* Fabio Barbieri nasceu em 14 de maio de 1970, em São Paulo, SP. É professor da Faculdade de Economia, Administração e Contabilidade de Ribeirão Preto da Universidade de São Paulo (FEA-RP/USP), além de Editor Adjunto e membro do Conselho Editorial de MISES: Revista Interdisciplinar de Filosofia, Direito e Economia. Cursou o bacharelado em Administração Pública na Fundação Getúlio Vargas de São Paulo (FGV-SP) e o mestrado e o doutorado em Economia pela USP. Foi professor da Universidade Presbiteriana Mackenzie e do Centro Universitário FECAP. É autor de diversos artigos acadêmicos publicados em diferentes periódicos e dos livros História do Debate do Cálculo Econômico Socialista (Instituto Ludwig von Mises Brasil, 2013) e A Economia do Intervencionismo (Instituto Ludwig von Mises Brasil, 2013), bem como, coautor das obras Manual de Microeconomia (Editora Atlas, 2011) e Metodologia do Pensamento Econômico: O Modo de Fazer Ciência dos Economistas (Editora Atlas, 2013).

E-mail: barbieri@mises.org.br
} 
O aniversário de quarenta anos do prêmio Nobel conferido a F. A. Hayek (18991992) nos oferece a oportunidade de refletir sobre o significado da obra desse autor. Apesar da volumosa literatura secundária dedicada às suas contribuições ${ }^{1}$, ainda falta, especialmente em português ${ }^{2}$, artigos que introduzam o leitor ao pensamento hayekiano. De fato, não seria exagero dizer que, dentre os grandes economistas, Hayek talvez seja o menos conhecido e compreendido, tanto pelos economistas profissionais quanto pelo público em geral.

Qualquer tentativa de síntese de suas ideias na forma de um artigo enfrenta dificuldades consideráveis. A mais óbvia delas se refere à amplitude de interesses: suas contribuições versam sobre teoria monetária, ciclos econômicos, teoria do capital, planejamento central, competição, filosofia

\footnotetext{
1 Mencionaremos alguns trabalhos. Para biografias de Hayek, ver: EBENSTEIN, Alan. Friedrich Hayek: a Biography. New York / Basingstoke: Palgrave for St. Martin's Press, 2001; CALDWELL, Bruce Hayek's Challenge: an Intellectual Biography of F.A. Hayek. Chicago: Chicago University Press, 2004. O primeiro foi escrito por autor que rejeita as teses econômicas de Hayek e o segundo é focado em aspectos metodológicos. Para livros sobre diferentes contribuições de Hayek, ver O'DRISCOLL, Jr. Gerald. Economics as a Coordination Problem: The Contributions of Friedrich A. Hayek. Kansas City: Sheed Andrews and McMeel, Inc, 1977; STEELE, G. R. The Economics of Friedrich Hayek. New York: Palgrave Macmilian, 2007. Para artigos de importantes economistas discutindo o significado das idéias econômicas do autor, ver: MACHLUP, Fritz. Hayek's Contribution to Economics. In: MACHLUP, Fritz (Ed.). Essays on Hayek. New York: NYU Press, 1976; SHACKLE, G. L. S. Hayek as Economist. In: SHACKLE, G. L. S. Business, Time and Thought. New York: NYU Press, 1988. Para coletâneas de artigos sobre Hayek, ver: BIRNER, Jack e ZIPJ, Rudy (Eds.) Hayek, Co-ordination and Evolution. London: Routledge, 1994 e FESER, Edward (ed.) Cambridge Companion to Hayek. Cambridge: Cambridge University Press, 2007.

${ }^{2}$ Nessa língua, ver MOREIRA, José Manuel Filosofia e Metodologia da Economia em F. A. Hayek. Porto: Publicações da Universidade do Porto, 1994; BUTTLER, Eamonn. A Contribuição de Hayek às Idéias Políticas e Econômicas de Nosso Tempo. Rio de Janeiro: Instituto Liberal-Nórdica, 1987.
}

das ciências sociais, teoria da mente, Filosofia Política, história das ideias, teoria de evolução institucional e Direito. Essa variedade de temas desafia qualquer estudioso de sua obra em nossa época de especialistas. A amplitude de interesses, além disso, sobrepõe-se a profundidade de conhecimento: em marcado contraste com aqueles autores que reclamam originalidade revolucionária, em cada um dessas áreas Hayek mostra grande erudição ao traçar em detalhes a evolução das tentativas prévias de resolver um problema antes de oferecer sua própria contribuição, necessariamente incremental.

Obstáculo correlato é posto pela forma de expressão do autor. Hayek não nos deixou nenhum tratado geral que articule suas teses em uma explicação integrada dos fenômenos sociais, embora estejamos de fato diante uma teoria social ampla, baseada na teoria econômica. Mas, especialmente nessa última área, suas ideias são geralmente expostas na forma de artigos dirigidos à comunidade acadêmica, artigos esses que refletem engajamento na discussão crítica de ideias. De fato, o autor participou de controvérsias com vários dos principais economistas de seu tempo. O entendimento de suas posições, dessa maneira, não pode ser dissociado do contexto desses debates e requer conhecimento das diversas teorias existentes no período.

Tampouco pode o analista perder de vista que as ideias de Hayek são firmemente calcadas na tradição da Escola Austríaca de Economia e que a pesquisa continental em geral tendia a ser ignorada pelos economistas de língua inglesa. Elementos tipicamente austríacos, como a ênfase no subjetivismo, a importância do aspecto temporal e a teoria do capital dessa escola são centrais nas teorias econômicas do autor.

Deve-se somar a isso o fato de que as suas convicções filosóficas e políticas também destoavam das crenças positivistas e intervencionistas predominantes no século vinte. Diante do dilema frequente na Economia entre relevância por um lado e tratabilidade formal e operacionalidade 
empírica por outro, Hayek nunca se furtou de se dedicar aos problemas que considerava mais importantes, o que o levou por vezes a problemas intrincados e temas impopulares.

As razões expostas acima mostram porque Hayek foi e continua sendo o economista cujas ideias foram mais incompreendidas e distorcidas pelos críticos. Sua explicação para as flutuações econômicas é geralmente analisada sem referências aos elementos característicos da teoria austríaca do capital ou interpretada em termos dos agregados macroeconômicos não utilizados pelo autor ${ }^{3}$. O chamado "problema do conhecimento", central em sua contribuição à teoria austríaca do processo de mercado, évisto ora como um problema apenas de assimetria de informações ${ }^{4}$, ora como algo que requereria pesquisas empíricas sobre o conhecimento dos agentes ${ }^{5}$, novamente a despeito da negação explicita dessa interpretação por parte do autor. Sua participação no debate sobre o cálculo econômico socialista é vista ora como uma lista de objeções práticas (não teóricas) ao planejamento central ${ }^{6}$, ora como algo que nega a necessidade de propriedade privada para o funcionamento dos mercados ${ }^{7}$. O mesmo fenômeno se repete nas diferentes leituras de suas teses filosóficas e políticas.

Além do caráter multidisciplinar de suas teorias, da defesa de opiniões minoritárias pouco conhecidas e do problema gerado pela leitura fragmentada por parte de seus críticos, devemos considerar ainda a

${ }^{3}$ COWEN, Tyler. Risk and Business Cycles: New and Old Austrian Perspectives. London: Routledge, 1997.

${ }^{4}$ STIGLITZ, Joseph. Whither Socialism? Cambridge: The MIT Press, 1994.

5 HUTCHINSON, Terence W. The Politics and Philosophy of Economics: Marxians, Keynesians, and Austrians. Oxford: Blackwell, 1981.

${ }^{6}$ LIPPINCOTT, Benjamin E. (Ed.). On The Economic Theory of Socialism. New York: McGraw-Hill, (1965) [1938].

${ }^{7}$ HOPPE, Hans-Hermann. Socialism: A Property or Knowledge Problem? Review of Austrian Economics, Vol. 9, No. 1, 1996. dificuldade inerente de alguns dos problemas abordados, o que tornava sua prosa nem sempre clara. A despeito de todas essas dificuldades interpretativas, ainda assim é possível oferecer uma síntese do pensamento de Hayek, pois existem elementos comuns em toda sua obra que justificam a caracterização de um programa unitário de pesquisa, cujas peças se encaixam como em um quebracabeça, capaz de oferecer uma explicação ampla dos fenômenos sociais.

O objetivo deste artigo é introduzir o pensamento hayekiano a partir da exposição dessetema central,ilustrandosua centralidade em algumas das principais teorias do autor. Adotaremos uma ordem mais ou menos cronológica de menção a essas teorias não para oferecer ainda outra interpretação da evolução do pensamento de Hayek, que trace influências intelectuais e históricas sobre suas crenças, mas, pensando na unidade da obra do autor, para ilustrar como ideias também apresentam consequências não intencionais: diferentes e novos aspectos do mesmo tema central se fazem presentes conforme este último é empregado no exame de problemas diversos. Tendo em vista esse objetivo, nos permitiremos utilizar o referencial analítico maduro do autor para ilustrar também suas obras da juventude, nas quais vários elementos do referencial explanatório ainda eram embrionários ou mesmo desconhecidos.

Iniciemos com a exposição do tema central da obra de Hayek. O sistema hayekiano se baseia no exame das implicações sociais do caráter falível do conhecimento humano. $\mathrm{O}$ florescimento humano, em tal sistema explanatório, nos coloca em situações nas quais o potencial para a existência de erros é necessariamente maior, de modo que a única maneira efetiva de correção desses erros é através do uso de mecanismos descentralizados de aprendizado, que por sua vez requerem liberdade individual. As ideias econômicas, filosóficas e políticas de Hayek têm como tema comum a liberdade como requisito para o crescimento do conhecimento. 
Essa, que é a conclusão principal de tal sistema, é sintetizada nas palavras do próprio autor:

[...] o argumento a favor da liberdade individual repousa principalmente no reconhecimento da inevitável ignorância de todos nós a respeito da maioria dos fatores dos quais a realização de nossos fins e bemestar dependem ${ }^{8}$.

Tornemos o argumento mais detalhado. A conexão no pensamento de Hayek entre as limitações do conhecimento humano e a liberdade se revela quando examinamos a relação entre esse conhecimento e a complexidade do problema econômico fundamental. Não utilizo a expressão usual "problema alocativo" porque esta é comumente associada a uma visão demasiada simplificada do problema real, segundo a qual meios escassos dados são alocados a fins alternativos conhecidos. O problema real, na concepção de Hayek, é mais amplo: dele faz parte a descoberta de novos meios e fins, de modo que o funcionamento de uma economia depende mais da contínua adaptação ao fluxo de contínuas mudanças do que da obtenção em dado momento de uma alocação perfeitamente eficiente. Os indivíduos devem continuamente criar e descobrir novos meios para antecipar as incertas demandas do futuro, a partir da adaptação dos projetos de investimentos herdados do passado.

Pois bem, conforme esse processo de descoberta se materializa em progressiva prosperidade, mais complexo será a tarefa de coordenação das ações individuais, pois se aprofunda o grau de divisão do trabalho e do capital e o conhecimento dos agentes se torna mais fragmentado: cada indivíduo tem cada vez menos condições de entender todas as etapas dos processos produtivos e imaginar

\footnotetext{
${ }^{8}$ HAYEK, F. A. The Constitution of Liberty. Chicago: The University of Chicago Press, 1979. p. 29. No original: "It is that the case for individual freedom rests chiefly on the recognition of the inevitable ignorance of all of us concerning a great many of the factors on which the achievements of our ends and welfare depends".
}

quais são as vias alternativas de uso para os recursos.

Mas, se o crescimento econômico requer processos produtivos mais complexos, que exigem a coordenação das ações de todos os agentes, como contornar a limitação imposta pelo caráter cada vez mais disperso e falível do conhecimento individual? Hayek mostra em sua obra como, a partir de certo grau de complexidade, esse obstáculo só pode ser contornado por meio da operação de mecanismos descentralizados de correção de erros, mecanismos esses que dispensam a necessidade de que cada agente compreenda os detalhes de como suas ações se relacionam com as dos demais. Em outros termos, o progresso necessariamente exige dos agentes econômicos progressiva alienação, no sentido marxista desse termo.

Chegamos com isso à caracterização mais aceita do tema central da pesquisa de Hayek. Gerald P. O'Driscoll identifica esse tema como o problema da coordenação9. O problema central das ciências sociais, para Hayek, requer a explicação da emergência da coordenação dos planos e ações dos agentes.

Essa coordenação deve levar em conta a complexidade do problema econômico fundamental e o caráter limitado do conhecimento humano. Diversos arranjos institucionais podem ser então comparados em termos de sua capacidade de induzir coordenação. A caracterização do programa de pesquisa hayekiano como algo que gira em torno do problema da coordenação, além de bem aceita na comunidade acadêmica austríaca, tem a vantagem de ser endossada pelo próprio Hayek, no prefácio que escreveu para o livro de O'Driscoll.

Vejamos como várias das contribuições teóricas do autor de fato dizem respeito a esse problema. A participação de Hayek no debate sobre o cálculo econômico socialista pretende mostrar a impossibilidade de se obter coordenação via planejamento central, dada a com-

\footnotetext{
${ }^{9}$ O'DRISCOLL Jr., Gerald. Economics as a Coordination Problem: The Contributions of Friedrich A. Hayek. Kansas City: Sheed Andrews and McMeel, Inc, 1977.
} 
plexidade do problema econômico. As críticas do autor ao mau uso do conceito de equilíbrio naquele debate e o desenvolvimento de sua própria interpretação do funcionamento dos mercados como processo de descoberta argumentam pela superioridade de mecanismos descentralizados de interação para resolver o problema de coordenação. Seus escritos sobre teoria do capital adicionam mais complexidades ao considerar o elemento de coordenação intertemporal dos planos de produção. Sua teoria monetária mostra que, apesar da importância do dinheiro para viabilizar mais progresso via especialização, variações na oferta monetária distorcem preços relativos e perturbam o equilíbrio intertemporal. A teoria austríaca dos ciclos econômicos, por sua vez, mostra como essas perturbações monetárias estão por trás das alterações na estrutura do capital que constituiriam as flutuações econômicas. Ou seja, tais flutuações na produção são vistas como um fenômeno de descoordenação intertemporal induzida por fenômenos monetários. A teoria da evolução institucional de Hayek, por sua vez, investiga a emergência da coordenação a partir do uso de regras que não foram desenhadas conscientemente ou mesmo compreendidas pela maioria.

Tendo em vista esse conjunto de temas, podemos notar que Hayek faz parte da tradição, retomada no presente pela abordagem interdisciplinar da complexidade, caracterizada pela investigação da emergência de estruturas ordenadas, com frequência adaptativas, formadas a partir da interação local de elementos ou agentes que seguem regras relativamente simples. No âmbito dos fenômenos sociais, o grau de complexidade existente nas economias modernas, que exige a coordenação das ações de milhões de pessoas, só seria alcançável mediante a existência das “ordens espontâneas" estudadas por Hayek, cuja adaptabilidade não seria replicável pelos rígidos mecanismos alocativos criados conscientemente pelos homens.

A complexidade do problema da coordenação se associa intimamente com o caráter limitado do conhecimento dos agentes cujas ações devem ser coordenadas, como afirmamos no início deste artigo. Com efeito, os limites do conhecimento se fazem presentes nas diversas teorias do autor.

Na economia de Hayek, a utilização do sistema de preços possibilita que agentes compatibilizem seus planos, mesmo que cada um destes contemple explicitamente fração muito pequena do conhecimento sobre os fundamentos da economia necessária para essa compatibilização, caso fosse tentada de forma consciente e centralizada. A liberdade proporcionada pela descentralização, por sua vez, permite que cada um discorde dos preços estabelecidos, à luz de sua opinião particular sobre o estado de fatores locais e suas projeções sobre o futuro, conjecturas essas que informam seus planos de negócios que são submetidas ao teste da lucratividade.

Na filosofia de Hayek, a preferência dos intelectuais pela coordenação centralizada (hierárquica) sobre ordens espontâneas formadas pela livre interação nos mercados é explicada pela adoção de uma forma de racionalismo (construtivista) que ignora as limitações do conhecimento. A pretensão de conhecimento dos intelectuais confunde, no domínio social, o conhecimento teórico do pesquisador, necessariamente genérico e abstrato, com o conhecimento prático dos agentes, sempre disperso e cambiante, sendo este último o relevante para a solução do problema da coordenação.

As tendências positivistas reinantes nas ciências sociais modernas, que induzem a desconsideração das limitações do conhecimento, levam ao desprezo pelas instituições que promovem o crescimento desse conhecimento: a liberdade para tentar soluções diferentes e os mecanismos descentralizados de correção de erros. O empirismo moderno, além disso, ao tratar como científico apenas aquilo que pode ser medido, ignora as relações entre os elementos de estruturas em favor de conceitos excessivamente agregados, alimentando a ilusão de controle de fenômenos sociais complexos. 
Na política de Hayek, a liberdade como instrumento de progresso também surge por meio de um processo de aprendizado por tentativas e erros: a evolução cultural de normas impessoais de conduta. As instituições compatíveis com a prosperidade não foram fruto da razão aplicada aos problemas sociais, mas emergiram como consequências não intencionais da interação entre agentes com conhecimento limitado. $\mathrm{Na}$ investigação hayekiana das origens do totalitarismo, tanto o impulso controlador derivado do racionalismo construtivista quanto os instintos morais herdados de um passado tribal se rebelam contra o caráter abstrato e impessoal das normas que possibilitam o aprendizado descentralizado que viabiliza a civilização.

A escolha dos elementos de conhecimento falível e complexidade do problema da coordenação, utilizados para caracterizar a pesquisa de Hayek, sugere igual importância para ambos. Por um lado, como notou o próprio autor ${ }^{10}$, os avanços da teoria econômica moderna refletiram a incorporação na teoria de elementos subjetivos, como as noções de preferências, estratégias, planos de ação e expectativas. Por outro lado, o problema da coordenação requer que cada agente formule planos consistentes com a sempre cambiante e diversa realidade exterior a qualquer indivíduo em particular, realidade que inclui as tecnologias de produção, as dotações de recursos, os planos dos demais e suas preferências, além das restrições institucionais.

Não basta, portanto, o subjetivismo: além do elemento criativo inerente ao conhecimento dos agentes, devemos levar em conta, em uma explicação sobre a emergência de ordem nos mercados, a existência dos dados exteriores que podem tornar tal

\footnotetext{
${ }^{10}$ HAYEK, F. A. The Counter-Revolution of Science. Indianapolis: Liberty Press, 1979 [1952]. p. 52: "And it is probably no exaggeration to say that every important advance in economic theory during the last hundred years was a further step in the consistent application of subjectivism".
}

conhecimento errôneo. Tampouco podemos, como faz a teoria econômica convencional, supor implicitamente a identificação automática entre o conhecimento dos agentes e realidade externa. No referencial teórico hayekiano, temos uma teoria sobre o crescimento do conhecimento que inclui a diversidade de conjecturas potencialmente rivais sobre condições mercadológicas locais e um mecanismo de correção de erros fornecido pelo teste de lucratividade, unindo dessa forma os aspectos subjetivos e externos do problema econômico. A moderna teoria austríaca de processo de mercado toma como base o chamado "problema do conhecimento" de Hayek, que indaga se (e como) o conhecimento subjetivo dos agentes converge para crenças compatíveis com os fundamentos da economia. Em outros termos, investiga as condições para que haja uma tendência a maior coordenação das ações.

A Economia do Conhecimento de Hayek pode ser interpretada, desse modo, como uma manifestação da epistemologia evolucionária ${ }^{11}$, que estuda o crescimento do conhecimento falível via variação e seleção em diferentes contextos, como a adaptação de seres vivos em seus ambientes, o problema da coordenação nos mercados ou a evolução do conhecimento na ciência. Esse referencial inclui tanto a hipótese de existência de realidade exterior ao indivíduo quanto o reconhecimento das imperfeições das teorias criadas para representar tal realidade. No modelo evolucionário hayekiano, em particular, a crescente dificuldade de coordenar ações de agentes em economias progressivas é superada graças à liberdade empresarial para testar soluções mercadológicas diferentes. A epistemologia evolucionária nos oferece assim um referencial natural para expor a temática central de Hayek, atendendo a

\footnotetext{
11 Ver: BARTLEY III, William W. \& RADNITZKY, Gerald (Eds.). Evolutionary Epistemology: Rationality and the Sociology of Science. La Salle: Open Court, 1987.
} 
demanda pelos dois elementos centrais de nossa caracterização da pesquisa de Hayek.

$\mathrm{O}$ referencial da epistemologia evolucionária sugere afinidades entre as obras de F. A. Hayek e as de seu amigo Karl Popper (1902-1994), também associado à mesma tradição ${ }^{12}$. As conexões exploradas por W.W. Bartley, III (1934-1990) entre as ideias de ambos, porém, não são amplamente reconhecidas devido a questões de preferências metodológicas. Como Popper é lembrado por uma versão simplista do critério falseacionista e não pela proposta de uma filosofia falibilista, mais fundamental em sua obra, os austríacos mantêm alguma distância do autor, inclusive para interpretar Hayek, a despeito da adesão explícita deste último a uma versão modificada da filosofia de Popper.

Neste ponto da análise, porém, não estamos interessados por temas puramente metodológicos. A menção a Popper foi feita porque este autor é central na discussão sobre a unidade do pensamento hayekiano. Do mesmo modo que utilizamos a epistemologia evolucionária para argumentar em favor dessa unidade, Terence W. Hutchinson (19122007) utiliza Popper para defender a existência de uma ruptura entre o pensamento de um Hayek I, comprometido com o apriorismo misesiano e um Hayek $\mathrm{II}^{13}$, que a partir de seu artigo mais importante ${ }^{14}$ teria se convertido ao falseacionismo popperiano, gerando dessa maneira uma reviravolta empiricista em seu pensamento metodológico e teórico.

Bruce Caldwell, por sua vez, relativiza tanto o apriorismo de Hayek I quanto a existência de influência popperiana no início de Hayek $\mathrm{II}^{15}$. Em vez de guinada

\footnotetext{
${ }^{12}$ Ver: POPPER, Karl R. Objective Knowledge. Oxford: Clarendon Press, 1972.

${ }^{13}$ HUTCHINSON. The Politics and Philosophy of Economics.

${ }^{14}$ HAYEK, F. A. Economics and Knowledge. Economica N.S. 4, p. 33-54, 1937.

15 CALDWELL, Bruce. Hayek's Transformation. History of Political Economy. Vol. 20, No. 4, 1988.
}

metodológica, Caldwell afirma que o mesmo artigo de 1937 marca a "transformação de Hayek" de economista técnico em cientista social mais amplo, transformação essa causada pela desilusão com as limitações da noção de equilíbrio para explicar o problema da coordenação.

Jack Birner, em contraste com os dois autores acima mencionados, acredita na unidade do pensamento de Hayek ${ }^{16}$. Esse pensamento formaria um programa de pesquisa caracterizado pela obediência a um conjunto de regras metodológicas e pelos desdobramentos do problema inicial enfrentado por Hayek, que trata de explicar os ciclos econômicos como um fenômeno de desequilíbrio causado por fatores monetários, tomando como base uma versão intertemporal da teoria de equilíbrio geral. Essa tese também foi criticada por Caldwell ${ }^{17}$, que nega que Hayek teria seguido conjunto constante de regras metodológicas listadas por Birner.

Como não buscamos saber quais fatores subjetivos explicariam as escolhas tomadas por Hayek em sua carreira, mas apresentar o conjunto das ideias em si mesmas do autor, com o propósito de expor ferramenta útil de análise, a tese da descontinuidade nos traria problemas apenas se existissem significativas incompatibilidades entre diferentes subconjuntos das teses teóricas desenvolvidas pelo autor. No entanto, este não é o caso. Hayek nunca renegou a teoria austríaca do capital, sua teoria de ciclos ou suas contribuições ao debate sobre o cálculo econômico socialista. Sua obra madura, pelo contrário, com frequência emprega esse conhecimento na base de sua interpretação ampliada dos fenômenos sociais.

Aevolução dopensamentometodológico do autor tampouco gerou alterações na natureza de suas pesquisas, que continuaram

\footnotetext{
16 Ver, por exemplo: BIRNER, Jack. Introduction: Hayek's Grand Research Programme. In: BIRNER, Jack \& ZIJP, Rudy van (Eds.) Hayek, Co-ordination and Evolution. London: Routledge, 1994.
}

${ }^{17}$ Ver Apêndice 2 de: CALDWELL. Hayek's Challenge. 
aliando teoria dedutiva abstrata, crítica das ideias e estudos históricos. De qualquer modo, no momento apropriado mostraremos como o popperianismo preferido por Hayek, adaptado para fenômenos complexos, não o afasta em absoluto da tradição metodológica austríaca.

A postura de Hayek em relação ao conceito de equilíbrio, por sua vez, pode de fato ser explicada pelas diferentes situações problemas com as quais se deparou e não por alguma guinada acentuada de suas ideias. Tomar o modelo de equilíbrio competitivo como resumo da operação de fatores microeconômicos a partir do qual se constrói uma teoria macroeconômica difere substancialmente da crença de que a teoria de equilíbrio, originalmente utilizada para descrever o funcionamento da competição, possa ser utilizada para substituir mercados reais por um modelo de planejamento central baseado nessa mesma teoria.

Quando lidamos com fenômenos complexos, influenciados por uma miríade de causas atuando simultaneamente, existe uma assimetria fundamental entre explicação por um lado e previsão e controle por outro. Nesse caso, explicações não pretendem gerar previsões acuradas, mas apenas ilustrações abstratas dos princípios de atuação de certas causas. Sendo assim, certas simplificações teóricas, adequadas para explicar certos fenômenos, perdem sua legitimidade quando usadas para controlá-los, pois ignoram tanto os demais fatores atuantes quanto, por exemplo, relações estruturais deixadas de lado pelas simplificações que procuram representar algum aspecto do fator causal.

É certo que o mau uso da construção de equilíbrio está relacionado com o desenvolvimento, a partir do artigo de 193718, de uma teoria de processo de mercado mais completa, que em vez de supor a existência da coordenação, busca explicar os processos que levariam ou não à sua emergência por meio de modelo de aprendizado por tentativas

\footnotetext{
${ }^{18}$ HAYEK. Economics and Knowledge.
}

e erros. Mas a extensão do modelo não é incompatível com os usos apropriados da teoria de equilíbrio e por isso não representa ruptura, mas desenvolvimento.

Tampouco representa ruptura significativa a extensão do modelo para o estudo da evolução das instituições compatíveis ou não com mercados livres e o progresso ou a integração da teoria econômica com elementos filosóficos e políticos. A narrativa comum, adotada inclusive pelo próprio autor, segundo a qual este teria abandonado a teoria econômica em favor de outros interesses supõe a aceitação muito apressada da identificação de "teoria econômica" apenas com os modelos assim classificados pelos economistas contemporâneos. No entanto, ninguém afirmaria que Douglas North, por exemplo, teria abandonado a teoria econômica devido a sua preocupação com instituições ou que não se possa classificar como análise econômica o sistema multidisciplinar desenvolvido por Karl Marx (1818-1883). Hayek, assim como Marx, foi um dos poucos economistas a construir um sistema interpretativo amplo dos fenômenos sociais, tomando como fundamento um conjunto de ferramentas econômicas.

Depois de apresentar o tema central da obra de Hayek - a liberdade como parte de mecanismo descentralizado de aprendizado capaz de contornar as limitações do conhecimento humano necessário para coordenar as ações em sistemas progressivamente mais complexos - resta-nos visitar algumas das teorias desenvolvidas pelo autor com o propósito de ilustrar esse tema. Nessa visita, serão destacados como essenciais para as explicações teóricas do autor tanto os pressupostos sobre conhecimento limitado quanto a caracterização das complexas estruturas que constituem o ambiente no qual ocorre a ação humana. Iniciemos com seus trabalhos sobre moeda e ciclos.

Os primeiros esforços teóricos do autor resultaram no desenvolvimento da Teoria Austríaca dos Ciclos Econômicos (TACE) 
sugerida por Ludwig von Mises (1881-1973) ${ }^{19}$. Segundo essa teoria ${ }^{20}$, o ciclo se inicia a partir de distúrbios de origem monetária. Na versão madura da TACE, em particular, examinamse as consequências de expansão do crédito levado a cabo pelo sistema bancário. $\mathrm{O}$ aumento do estoque de moeda, contudo, não afeta todos os preços simultaneamente: as alterações de preços dependem dos mercados nos quais ocorre a injeção monetária inicial e dos particulares canais de propagação dessa expansão. A distorção dos preços relativos resultante disso altera a estrutura do capital de maneira incompatível com as preferências subjacentes. A crise econômica consiste no processo de reestruturação da produção que ocorre quando se manifesta a descoordenação intertemporal entre os planos dos agentes.

No mercado de fundos emprestáveis, a injeção de crédito representa deslocamento da curva de oferta, induzindo taxa de juros de mercado inferior à taxa natural, definida como aquela que coordenaria investimento e poupança na ausência de distúrbios monetários. O maior investimento resultante disso assume a forma de um aprofundamento da estrutura do capital: iniciam-se projetos com maturação mais longa. Durante a fase ascendente do ciclo, porém, a maior demanda pelo fator trabalho nesses projetos gera uma renda que se planeja gastar segundo o padrão original de preferência temporal, resultando em uma demanda por bens finais que não pode ser atendida pelas firmas comprometidas com uma estrutura de produção mais voltada para o futuro, que ainda não maturou. Os preços dos bens de consumo sobem e a lucratividade dos projetos originais declina, já que não existem bens de capital complementares para concluí-los. O ciclo ocorre porque a incompatibilidade de planos não é revelada

\footnotetext{
${ }^{19}$ MISES, Ludwig von. Theory of Money and Credit. Indianapolis: Liberty Fund, 1981 [1912].

20 Para uma exposição moderna da mesma, ver: GARRISON, Roger. Time and Money. London: Routledge, 2000.
}

instantaneamente, pois a transição para uma estrutura do capital mais alongada demanda tempo.

Os elementos característicos da TACE são justamente aqueles mais distantes da macroeconomia convencional, o que explica as dificuldades associadas a sua interpretação: o uso de estruturas no lugar de variáveis agregadas. Variáveis como aquelas associadas à equação de trocas da teoria monetária dão lugar ao "efeito Cantillon", o estudo das consequências das alterações em preços relativos causados por distúrbios monetários. O capital como fundo homogêneo, por sua vez, cede espaço à noção de estrutura temporal do capital, segundo a tradição austríaca ${ }^{21}$. Vejamos mais de perto como Hayek trata da relação entre a estrutura de preços relativos e mudanças na estrutura do capital.

Em um de seus primeiros artigos ${ }^{22}$, Hayek argumenta que a moeda seria não neutra, mesmo diante de política monetária voltada à estabilidade do nível geral de preços. Se tomarmos uma noção de equilíbrio geral adaptada a um contexto intertemporal, no qual os agentes antecipam perfeitamente mudanças esperadas, como por exemplo efeitos sazonais ou derivados de mudanças tecnológicas permanentes, poderíamos esperar que os preços variassem ao longo da vigência de tal equilíbrio, de modo que a política de estabilização do nível de preços no mesmo período perturbaria o equilíbrio intertemporal.

Como quer explicar o fenômeno da descoordenação macroeconômica, sob a forma de ciclos, Hayek não parte da hipótese de existência de recursos desempregados, pois isso constitui o próprio explanandum sob investigação. Em vez da abordagem empírica

21 Ver: BÖHM-BAWERK, Eugen von Capital and Interest. South Holland: Libertarian Press, 1959.

${ }^{22}$ HAYEK, F. A. Intertemporal Price Equilibrium and Movements in the Value of Money [1928]. In: HAYEK, F. A. Good Money, Part I: The New World - The Collected Works of F. A. Hayek, Volume 5. Chicago: The University of Chicago Press, 1999. 
favorecida por Wesley C. Mitchell (18741948), Hayek acredita que uma teoria dos ciclos deva ser sobreposta sobre o referencial analítico de equilíbrio, esta última capaz apenas de dar conta de forças equilibradoras que seguem distúrbios exógenos. Sendo assim, as explicações não monetárias do ciclo, conforme a classificação utilizada em seu primeiro livro ${ }^{23}$, dedicado à análise das teorias rivais, são rejeitadas pela sua incapacidade de fornecer explicação convincente para a existência de erros sistemáticos por parte dos empresários ${ }^{24}$. Esse tipo de teoria não deixa claro porque as forças equilibradoras de mercado ora atuariam, ora não. Por outro lado, embora a introdução de meio indireto de troca seja capaz de explicar o surgimento de erros sistemáticos, as explicações monetárias pecariam por seu interesse exclusivo no nível geral de preços.

Os ciclos, na teoria alternativa desenvolvida por Hayek, embora tenham origem monetária, são constituídos por mudanças reais na estrutura do capital. Para explicar a existência de erros sistemáticos, o autor adota em seu segundo livro $^{25}$ um modelo simplificado da estrutura do capital, reproduzido no diagrama abaixo. Cada barra listrada representa o valor do capital em cada estágio de produção, depois da aplicação dos fatores primários de produção, até que o capital circulante mature na forma de bens de consumo, na barra branca inferior.

${ }^{23}$ HAYEK, F. A. Monetary Theory and the Trade Cycle [1929]. In: HAYEK, F. A. Business Cycles: Part 1 - The Collected Words of F. A. Hayek, Volume 7. Chicago: University Of Chicago Press, 2012.

${ }^{24}$ Veja também a opinião expressa em outro texto: "The explanation that this is just due to a kind of psychological infection or that for any other reason most entrepreneurs should commit the same avoidable errors of judgment does not carry much conviction" (HAYEK, F. A. Price Expectations, Monetary Disturbances, and Malinvestments [1933]. In: HAYEK, F.A. Good Money, Part I. p. 236).

25 HAYEK, F. A. Prices and Production [1935]. In: HAYEK, F. A. Business Cycles: Part 1.

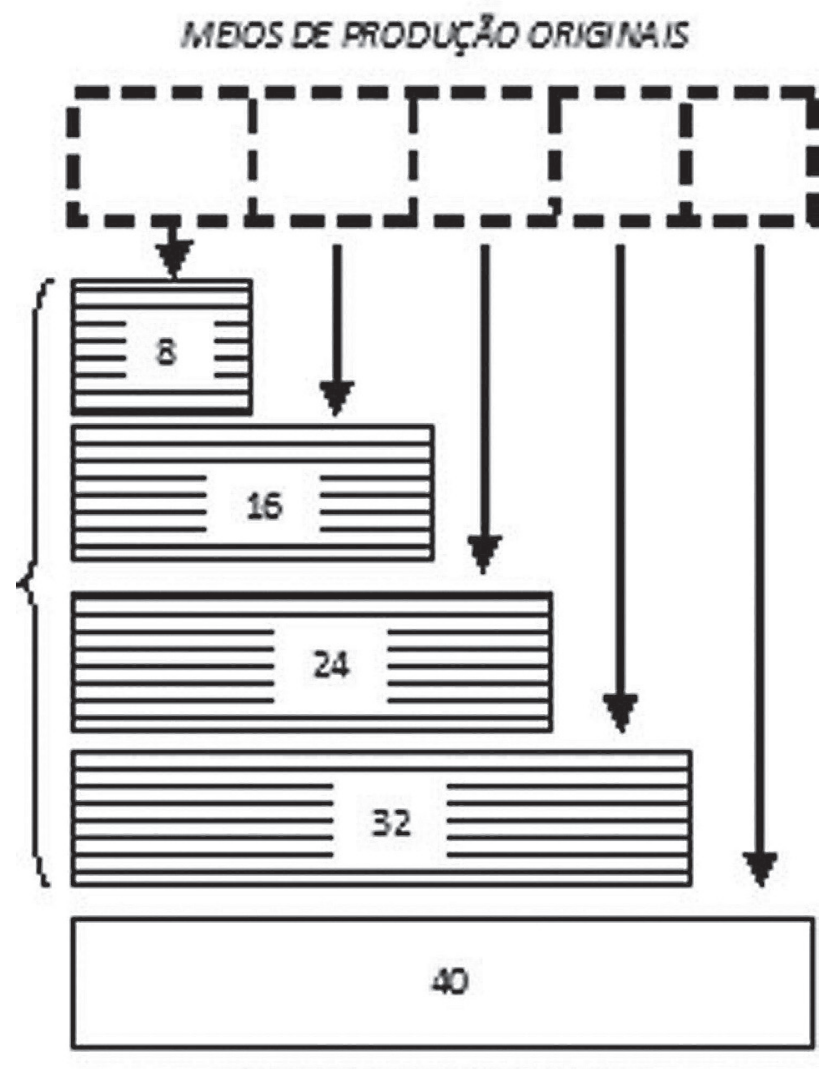

BENS DE CONSUMO FINAIS

Essa representação algo simplificada da estrutura do capital não impediu na comunidade acadêmica anglófona o estranhamento causado pela ênfase austríaca na dimensão temporal do capital. Parte dos esforços de Hayek desde a exposição de sua teoria foi dedicado a clarificar a importância da heterogeneidade temporal do capital $^{26}$ nas situações de crescimento e ciclos, para as quais a hipótese de sincronia de todas as etapas produtivas não se aplica. O livro seguinte ${ }^{27}$ de Hayek, de fato, reexpõe a mesma teoria, deixando de utilizar a nomenclatura austríaca da teoria do capital, mas enfatizando justamente os aspectos centrais desta última. Nesse livro, o autor responde a seus críticos supondo inicialmente desemprego de recursos, salários rígidos para baixo, imobilidade de trabalho entre setores no curto

\footnotetext{
${ }^{26}$ Ver, por exemplo: HAYEK, F. A. The Mythology of Capital. Quarterly Journal of Economics, Vol. 50, 1936.

${ }^{27}$ HAYEK, F. A. Profits, Interest and Investment. London: Routledge \& Kegan Paul, 1939.
} 
prazo e taxas de juros constantes, além da rigidez temporal na produção característica de sua teoria. Nessa exposição, o retorno a uma estrutura do capital menos aprofundada durante a crise não ocorre por indução de juros maiores, mas pelo "efeito Ricardo": salários menores em comparação com preços mais elevados dos bens de consumo, agora mais escassos, permitem a mesma substituição de capital por trabalho nessa fase do ciclo.

Embora a simplificação adotada com os "triângulos de Hayek" baste para indicar a existência de rigidez temporal na realocação do capital, central na teoria, a ordem específica de alterações nos preços e produção depende da forma como se representa a estrutura do capital. Em sua última obra sobre o tema ${ }^{28}$, Hayek procura generalizar essas formas, buscando representação mais sofisticada das alterações da estrutura do capital ao longo do tempo. Tal empreitada se deparou, no entanto, com os obstáculos impostos pela dificuldade de representar formalmente complexas estruturas do capital herdadas por agentes que tomam decisões voltadas para o futuro, o que requer a não menos difícil tarefa de incorporar a passagem do tempo à teoria econômica.

Enquanto era levado pelas teorias do capital e ciclos a considerar uma versão intertemporal da teoria de equilíbrio, que considera as noções de antevisão dos empresários e compatibilidade entre seus planos, uma nova interpretação da teoria de equilíbrio se manifestara: em vez de ser usada para explicar o funcionamento dos mercados, a teoria da competição passou a ser vista como ferramenta para substituí-los por planejamento central, durante o debate sobre o cálculo econômico socialista ${ }^{29}$. Firmas estatais seriam instruídas pelo planejador

\footnotetext{
${ }^{28}$ HAYEK, F. A. The Pure Theory of Capital. London: Routledge \& Kegan Paul, 1941.

${ }^{29}$ HAYEK, F. A. (Ed.) Collectivist Economic Planning., 1935. Reimpresso como: BOETTKE, Peter (Ed.) Socialism and the Market: The Socialist Calculation Debate Revisited - Vol. II, London: Routledge, 2001.
}

central a produzir até que os custos marginais fossem iguais aos preços de equilíbrio ditados centralmente, gerando dessa forma eficiência alocativa. Esse novo uso da teoria de equilíbrio levou Hayek a se dedicar ao desenvolvimento da teoria austríaca de processo de mercado, que procura explicar a emergência da coordenação de planos em vez de assumir sua existência, como faz a teoria de equilíbrio convencional.

A reação de Hayek às propostas de "socialismo de mercado" naquele debate foi a mesma de Mises: apontar para a insuficiência da teoria da competição perfeita para responder ao desafio original lançado por este último autor. Na teoria de equilíbrio geral, se os fundamentos da economia forem conhecidos (ordenamentos de preferência, tecnologias e dotações de recursos produtivos), pode-se de fato obter vetor único de preços e quantidades de equilíbrio, satisfeitas certas hipóteses. Para os austríacos, porém, o problema não seria replicar um equilíbrio estático, mas gerar mecanismo que inclui a descoberta empresarial de meios e fins ao longo do tempo, conforme o ambiente econômico se modifica continuamente.

As objeções hayekianas não são assim meramente práticas, relativas ao virtualmente infinito número de dados a serem considerados pelo planejador, mas apontam para as lacunas da teoria de equilíbrio. Se um agente tiver opinião minoritária sobre a escassez relativa de certo recurso em certa ocasião e local, por exemplo, deveria ele agir de acordo com suas expectativas ou apenas reagir passivamente segundo o preço paramétrico dado? Se os agentes tiverem opiniões diferentes sobre os usos alternativos dos recursos no futuro, as opiniões sobre os custos de oportunidades divergirão e as regras de custos não seriam auditáveis. Como saber, pergunta Hayek, qual seria o custo marginal que prevaleceria em ambiente competitivo sem a existência de um processo prévio que envolva rivalidade entre opiniões conflitantes? A objeção fundamental aos modelos de socialismo de mercado mostra que os "dados" considerados pela teoria de 
equilíbrio competitivo na verdade não existiriam sem a atividade competitiva prévia. Se o modelo de planejamento proíbe a rivalidade, não se pode supor que os agentes descubram novas maneiras de atender as necessidades, como ocorre com a competição real.

Tampouco a ênfase hayekiana no aprendizado dos agentes difere ou é incompatível com a tese misesiana sobre a centralidade da propriedade privada para o funcionamento dos mercados. De fato, na visão de Hayek o aprendizado supõe a possibilidade de opiniões diversas sujeitas à experimentação e, sem propriedade privada, não haveria liberdade para experimentar soluções rivais. Propriedade privada não aparece explicitamente nos textos referentes ao debate porque os socialistas de mercado propuseram modelos que excluíam tal instituição e a tarefa de Hayek era mostrar como tais modelos, nessas condições, não seriam capazes de resolver o problema econômico.

O debate induziu a explicitação de uma teoria mais completa sobre os fenômenos de mercado, que não se atenha apenas ao estado final de equilíbrio, mas que explique fora dele as condições para que haja tendência ao mesmo. O esboço dessa teoria de processo já foi apresentado no início do artigo, quando expomos a interpretação do mercado como um mecanismo de aprendizado por tentativas e erros capaz de gerar a coordenação das ações. O que nos resta fazer é examinar a seqüência de artigos que devem ser examinados para que o argumento de Hayek seja interpretado em seu contexto.

O primeiro e mais fundamental deles é o já mencionado artigo de 1937. Nele, Hayek argumenta que a noção de equilíbrio, identificada com a compatibilidade de planos durante a vigência do mesmo, não é consequência apenas do pressuposto de ação racional, pois cada plano pode conter hipóteses (empresariais) errôneas sobre os fundamentos da economia e planos dos demais agentes, o que leva à frustração de expectativas e descoordenação ${ }^{30}$. Para que tenhamos uma explicação para o grau de ordem observável nos mercados, devemos explicar porque o conhecimento subjetivo de cada um se torna compatível com a realidade subjacente: ou seja, devemos estudar o processo de aprendizado dos agentes.

A interpretação segundo a qual esse estudo seria de natureza empírica é explicitamente rejeitada pelo autor ${ }^{31}$. Uma teoria sobre aprendizado, em seu lugar, é sugerida em outro artigo sobreo tema ${ }^{32}$. Neste, a pergunta sobre como o conhecimento disperso dos agentes (que não pode ser confundido com o conhecimento formal do cientista) pode ser espontaneamente usado para obter um grau de coordenação não replicável por planejamento central é respondida através da interpretação do sistema de preços como uma linguagem. Essa linguagem dispensaria a necessidade de que os agentes conheçam os detalhes sobre os fundamentos da economia para que suas ações sejam coordenadas. Flutuações nos preços indicam alterações na escassez relativa dos bens, de maneira que cada agente ajusta suas demandas por fatores e bens finais, levando em conta em sua ação as causas iniciais que requereram os ajustes, mas sem saber quais foram essas causas.

Nesse artigo, Hayek torna explícito que o problema econômico relevante trata de "adaptação rápida a mudanças em circunstâncias particulares de tempo e espaço" 33 e que a existência de um sistema de preços funcionando

${ }^{30}$ HAYEK. Economics and Knowledge.
${ }^{31}$ Na página 53, Hayek afirma: "[...] and emphasizing
that the propositions about how people will learn ..., I do
not mean to suggest that there opens here and now a wide
field for empirical research. I very much doubt whether such
investigation would teach us anything new".
${ }^{32}$ HAYEK, F. A. The Use of Knowledge in Society. American Economic Review, Vol. 35, 1945. Em língua portuguesa o artigo foi publicado como: HAYEK, F. A. O Uso do Conhecimento na Sociedade. Trad. Philippe A. Gebara Tavares. MISES: Revista Interdisciplinar de Filosofia, Direito e Economia, Vol. I, No. 1, jan.-jun. 2013: 153-62.

${ }^{33}$ HAYEK. O Uso do Conhecimento na Sociedade. p. 158. 
como um sistema de telecomunicação permite a emergência da ordem espontânea dos mercados.

Este artigo tende a ser interpretado por economistas da informação como uma afirmação de que os preços comunicariam informação de forma eficiente. Essa tese atribuída a Hayek, porém, não se sustentaria, afirmam os críticos, pois se alguns agentes comprassem uma mercadoria agrícola porque os preços subiram, "pegando carona" naqueles que investiram em previsão do tempo, os preços não seriam perfeitamente informativos. Mas, considerando que para Hayek o mercado deve gerar adaptação fora do equilíbrio e não eficiência na alocação de recursos conhecidos, o valor informacional do sistema de preços na verdade repousa em outra parte.

O contraste entre a teoria de processo e a teoria de equilíbrio de mercado é analisado em outro artigo ${ }^{34}$, dedicado à discussão da noção de competição. A competição, para Hayek, seria um processo dinâmico cujas características essenciais são desprezadas pela teoria de equilíbrio. Normativamente, recomendações de regulação e intervenção baseadas nessa última desconsideram as atividades competitivas, como promoções, publicidade ou experimentação com variação de produto, essenciais para que os agentes descubram formas de atender necessidades. Nesse artigo, Hayek responde ao problema do conhecimento com uma concepção de competição que explicitamente fala em atividade de solução de problemas $^{35}$ através de mecanismo de aprendizado por tentativas e erros ${ }^{36}$. Para o autor:

A solução do problema econômico da sociedade é nesse sentido sempre uma viagem de exploração ao desconhecido, uma tentativa de descobrir novas maneiras de fazer as coisas melhor do que antes ${ }^{37}$.

\footnotetext{
${ }^{34}$ HAYEK, F. A. The Meaning of Competition [1946]. In: Individualism and Economic Order. Chicago: Chicago University Press, 1980.

${ }^{35}$ Idem. Ibidem. p. 96.

${ }^{36}$ Idem. Ibidem. p. 100.

${ }^{37}$ Idem. Ibidem. p. 101.
}

Adescriçãodomercadocomomecanismo evolucionário de aprendizado que envolve tanto a criatividade da descoberta empresarial quanto um mecanismo de correção de erros é consolidada em ainda outro artigo ${ }^{38}$. Nele, seu autor contrasta a "visão de engenheiro" que informa a presente interpretação do critério paretiano de eficiência - alocação ótima de recursos conhecidos - com sua opinião de que, se os mercados forem de fato mecanismos de descoberta, a competição deve ser valorizada justamente porque seus frutos não podem ser imaginados ex ante e portanto estimativas de seus benefícios concretos não podem ser realizadas, embora a liberdade de experimentação seja fundamental para o surgimento de inovações.

Esse tipo de conclusão, se relevante, se choca frontalmente com as crenças metodológicas que informam o economista do século vinte, que valorizam apenas aquilo que pode ser operacionável empiricamente. A convicção de Hayek sobre a importância de estruturas não facilmente representáveis formalmente, de aspectos subjetivos não mensuráveis e da emergência de novidade não antecipável o levou naturalmente à discussão metodológica, a qual nos voltamos agora.

Embora existam diferenças entre as concepções filosóficas de Mises e Hayek e seja verdade que o reconhecimento do problema do conhecimento implica que a emergência da coordenação não é redutível à lógica pura da escolha, as diferenças práticas entre as metodologias dois autores são em geral superestimadas. Ambos (bem como os demais membros da tradição austríaca) podem ser vistos como herdeiros da metodologia clássica, dominante até os anos vinte ${ }^{39}$.

${ }^{38}$ HAYEK, F. A. Competition as a Discovery Procedure. In: HAYEK, F. A. New Studies in Philosophy, Politics and Economics. London: Routledge, 1978.

${ }^{39}$ Ver: SENIOR, Nassau W. An Outline of the Science of Political Economy. New York: Augustus M. Kelley, 1965 [1836]; MILL, John Stuart. On the Definition of Political Economy, and on the Method of Investigation Proper to It. In: MILL, John Stuart. Essays on Some 
Nessa tradição, as peculiaridades metodológicas das ciências sociais eram atribuídas ao caráter "psicológico" (subjetivo) de seus conceitos e à complexidade inerente ao seu objeto estudo, que conspiram contra a possibilidade de testes empíricos cruciais. Em seu lugar, os clássicos (e os austríacos) defendiam a distinção entre a teoria pura, que deriva logicamente consequências de postulados bem gerais e a teoria aplicada, que emprega hipóteses históricas mais concretas. A observação empírica e histórica não testaria a validade da teoria pura, mas a aplicabilidade da mesma à situação particular.

Carl Menger (1840-1921), Ludwig von Mises e F. A. Hayek defendem versões dessa mesma tradição, a despeito de suas diferenças. Todos defenderão a teoria econômica dos ataques empiristas. Hayek, em particular, combaterá o positivismo, que mais tarde dominaria a Economia e oferecerá sua própria versão da metodologia clássica, com ênfase na complexidade dos fenômenos. Vejamos essas duas contribuições na sequência.

A crítica de Hayek ao positivismo se encontra em um livro ${ }^{40}$, publicado na década de cinquenta, no qual seu autor critica o programa positivista em ciências sociais e explora as consequências políticas de um racionalismo construtivista associado a esse positivismo, que busca moldar a sociedade segundo plano consciente, pretensamente racional.

Hayek emprega o termo "cientificismo" para descrever o programa que busca imitar nas ciências sociais aquilo que erroneamente se considerava o método das ciências físicas. O cientificismo seria caracterizado por seu coletivismo, que busca restringir a ciência ao uso de variáveis agregadas, sujeitas à

Unsettled Questions of Political Economy. Kitchener: Batoche Books, 2000 [1844]; CAIRNES, John Elliot. The Character and Logical Method of Political Economy. Kitchner: Batoche Books, 2001 [1888]; KEYNES, John Neville. The Scope and Method of Political Economy. Kitchener: Batoche Books, 1999 [1890].

${ }^{40}$ HAYEK, F. A. The Counter-Revolution of Science. Indianapolis: Liberty Press, 1979 [1952]. mensuração; pelo historicismo, ou crença na possibilidade de se derivar leis a partir do acúmulo de casos observados historicamente e também pelo objetivismo, que rejeita variáveis que dependam da percepção subjetiva dos agentes, não verificáveis intersubjetivamente. Mas, ao contrário da escassez de resultados gerados pelos defensores desse programa, as teorias econômicas que tiveram algum sucesso explanatório, aponta Hayek, foram baseadas no individualismo metodológico, que recomenda a explicação de fenômenos socais a partir da interação entre indivíduos; usaram simplificações abstratas, a partir das quais deduziam-se teoremas e se tornaram cada vez mais subjetivistas, incorporando noções como preferências, planos e expectativas.

A desconsideração pela complexidade e pelo subjetivismo que marcam o cientificismo, além disso, reduziria a capacidade do analista de perceber a formação de ordens espontâneas, induzindo a crença na capacidade de controle dos fenômenos sociais. Hayek utiliza como estudo de caso a transformação do cientificismo de Auguste Comte (1798-1857) e de Claude-Henri de Rouvroy (1760-1825), o Conde de Saint-Simon, em um projeto de engenharia social. Aqui, e em suas obras políticas posteriores, Hayek explora a relação entre o tipo de racionalismo que ignora as limitações do conhecimento humano e o advento de ideologias totalitárias. O desprezo pelo conhecimento fragmentado dos indivíduos em favor da crença de posse de conhecimento científico provado convida o engenheiro social a impor hierarquicamente um plano baseado em suas concepções pretensamente racionais.

A metodologia defendida por Hayek ${ }^{41}$, por sua vez, atualiza a tradição clássica, modificando a filosofia da ciência popperiana para lidar com fenômenos complexos. Estes últimos são identificados pelo número mínimo de variáveis necessárias para uma explicação aceitável do objeto estudado:

${ }^{41}$ HAYEK, F. A. The Theory of Complex Phenomena. In: Studies in Philosophy, Politics and Economics. 
embora possamos estabelecer relações precisas entre poucas grandezas de um fenômeno simples, os fenômenos complexos, como aqueles estudados pela Economia, são sempre influenciados por um sem número de variáveis.

Conforme aumenta o grau de complexidade do fenômeno estudado, menos aplicáveis se tornam os preceitos do cientificismo. Se estes forem aplicados, as teorias econômicas desenvolvidas pelo autor sobre fenômenos complexos, por exemplo, deveriam ser descartadas como pseudocientíficas e substituídas por modelos agregados, mesmo que distorções em preços relativos, modificações na estrutura do capital, aprendizados por tentativas e erros, emergência de coordenação e assim por diante fossem de fato fundamentais para explicar o mundo real.

Embora seja desejável que uma teoria seja falseável, Hayek aponta para um dilema metodológico: quanto maior o grau de complexidade do objeto estudado, menor será o conteúdo empírico de uma teoria que o estude, independente da postura dogmática ou aberta para a crítica de seu formulador. $\mathrm{O}$ estudo desse tipo de fenômeno permitiria apenas a formulação de predições de padrão (pattern predictions), que identificam algumas características em abstrato do fenômeno, sendo impossível determinar seus detalhes, dado o grande número de variáveis em questão, grande parte delas não observável. A teoria da evolução por seleção natural ou a teoria de equilíbrio geral, para Hayek, devem então ser entendidas não como instrumentos de controle, mas como a descrição abstrata de apenas algum aspecto dos fenômenos estudados. Aqui, novamente nos deparamos com uma visão cética sobre o potencial do conhecimento teórico para fins de engenharia social, em vez de seu uso correto como guia para análise institucional comparada.

Voltamos agora a considerar mais um campo no qual Hayek lida com estruturas complexas e desenvolve teoria que tem implicações sobre os limites do conhecimento humano. Em 1952 Hayek publica um livro $^{42}$ no qual propõe uma teoria sobre o funcionamento da mente que desenvolvera na década de 1920, livro esse que será conhecido como uma das contribuições fundadoras da teoria conexionista da mente. Embora pareça surpreendente um economista escrever sobre esse assunto, podemos notar inúmeras semelhanças entre a forma como o autor concebe o funcionamento dos mercados e da mente: esta também é vista como um sistema complexo adaptativo, composto por sinais transmitidos entre elementos de uma estrutura. Para que possamos identificar essas semelhanças, vejamos alguns elementos dessa teoria.

Hayek distingue entre três ordens de fenômenos: a ordem física do mundo externo, a ordem neural das fibras nervosas de nosso organismo (subconjunto da primeira) e a ordem mental das percepções sensoriai ${ }^{43}$. Ao contrário da crença vigente na época em que o livro foi escrito, o sistema nervoso central não conduz impulsos contendo propriedades do mundo físico: os estímulos que impressionam as células sensíveis do organismo resultam em impulsos que são associados aos elementos do mundo físico apenas por meio do caminho que percorrem ao passar pelo sistema nervoso.

Isso coloca então o problema de explicar como certas relações entre os objetos da ordem física são reproduzidas de alguma forma na ordem sensorial, já que esta não acessa diretamente a primeira. Para Hayek, ao longo da evolução das espécies e dos indivíduos, os organismos desenvolveram um sistema de diferenciação de estímulos segundo o qual cada um deles ocupa uma posição em uma ordem que representa o significado que esse estímulo (em combinação com outros estímulos) tem para o organismo ${ }^{44}$. Desse modo, a formação de uma representação relacionada com o mundo físico, ainda que de

${ }^{42}$ HAYEK, F. A. The Sensory Order. Chicago: The University of Chicago Press, 1976 [1952].

${ }^{43}$ Idem. Ibidem. p. 39.

${ }^{44}$ Idem. Ibidem. p. 42. 
forma imperfeita, confere vantagem evolutiva ao organismo.

A percepção sensorial e toda atividade mental são vistas então pelo autor como resultados de um aparato de classificação derivado de impulsos transmitidos por conexões formadas entre elementos de uma estrutura. Configurações de impulsos que ocorrem simultaneamente atingem fibras densamente conectadas entre si, percebidas como oriundas da mesma classe de estímulos.

Ao estudar a relação entre a formação de conexões no cérebro e os objetos físicos classificados por elas, Hayek utiliza a metáfora de um mapa, que consiste na representação das relações entre os estímulos que atuam no organismo, ou a rede de relações estáveis que definem a forma como percebemos o mundo ${ }^{45}$. A exposição do organismo a um meio ambiente particular resulta em um conjunto de estímulos que gera um padrão de impulsos que percorre esse mapa, resultando em um modelo ${ }^{46}$ ou interpretação desse meio.

Como na tradição conexionista em geral, a memória não é um local que armazena informações sensoriais trazidas pelos impulsos, mas consiste justamente nos padrões de relações formadas no cérebro ${ }^{47}$. Como a essência dos fenômenos mentais é a relação entre elementos de uma estrutura, essas relações poderiam concebivelmente ser replicadas em outros materiais, resultando na emergência desse tipo de fenômeno ${ }^{48}$.

Comonas demais teorias do autor, Hayek também discute aqui suas consequências metodológicas, enfatizando que a teoria da ordem sensorial permite apenas a descrição de padrões de funcionamento da mente e a formulação de previsões de padrão ${ }^{49}$. Além dessa limitação do poder explanatório de teorias referentes a fenômenos complexos,

\footnotetext{
${ }^{45}$ Idem. Ibidem. p. 109.

${ }^{46}$ Idem. Ibidem. p. 114.

${ }^{47}$ Idem. Ibidem. p. 52.

${ }^{48}$ Idem. Ibidem. p. 47.

${ }^{49}$ Idem. Ibidem. p. 34, 43, 182.
}

Hayek aponta outro limite do conhecimento humano, derivado de sua teoria da mente: uma explicação completa do cérebro seria impossível, na medida em que um aparato de classificação deve ter um grau de complexidade superior ao objeto classificado para que possa entendê-lo em todos seus aspectos, de modo que a mente nunca seria capaz de explicar completamente a si mesma ${ }^{50}$.

Neste ponto podemos novamente notar que, como nas suas outras teorias, também no estudo da ordem sensorial Hayek descreve um sistema auto-organizado: a mente é vista como um fenômeno emergente, constituído a partir de uma base material, mas que apresenta características diferentes dos elementos dessa base. A formação de uma ordem organizada é obtida por meio de processos evolucionários. Novamente, a essência da explicação envolve relações estruturais entre elementos que interagem localmente. Essa estrutura se adapta conforme entra em contato com os estímulos externos e envolve um processo de aprendizado que enfatiza as limitações do conhecimento.

A identificação desses elementos comuns leva naturalmente à analogia entre a teoria da mente e as teorias econômicas do autor: a propagação de impulsos através de uma estrutura de fibras nervosas lembra a adição de insumos produtivos a uma estrutura do capital ou ainda a transmissão, via sistema de preços, de sinais que permitem a coordenação nos mercados. Além dessas áreas, Hayek identificará também em sua teoria da evolução institucional, como veremos agora, a existência de ordens autoorganizadas com características análogas, de modo que podemos de fato reconhecer o papel central que as estruturas complexas e o conhecimento falível ocupam no programa de pesquisa do autor.

Tendo expandido a teoria de equilíbrio competitivo para um referencial mais amplo de processo de mercado, que busca explicar a emergência espontânea da coordenação

\footnotetext{
${ }^{50}$ Idem. Ibidem. p. 184-90.
} 
por meio de mecanismo de aprendizado por tentativas e erros, capaz de gerar adaptação ao perpétuo fluxo de mudanças de um modo que mecanismos de controle consciente não seriam capazes, nada mais natural do que ampliar novamente esse estudo comparativo para tratar explicitamente dos arcabouços institucionais que acompanham as diferentes formas de resolver o problema econômico fundamental.

Isso é de fato feito em outro subconjunto de obras do autor ${ }^{51}$, que reúnem elementos econômicos, filosóficos, históricos e políticos em uma visão de mundo integrada a respeito dos fenômenos sociais ${ }^{52}$, baseada, como afirmamos, em sua economia falibilista.

Um dos padrões complexos de que nos fala seus estudos metodológicos é o conceito de "ordem" em sociedade, estrutura reconhecida pela correspondência entre as expectativas sobre as formas de ação dos demais agentes e o comportamentoefetivodos mesmos. Existiriam dois tipos de ordens sociais: taxis, desenhadas conscientemente para certos propósitos e cosmos, ordens abstratas que evoluíram e não atendem a propósitos específicos.

\footnotetext{
${ }^{51}$ HAYEK, F. A. O Caminho da Servidão. Trad. Anna Maria Capovilla, José Ítalo Stelle e Liane de Morais Ribeiro. São Paulo: Instituto Ludwig von Mises Brasil, 6 $6^{\text {a }}$ Ed., 2010 [1944]; HAYEK, F. A. Os Fundamentos da Liberdade. Intr. Henry Maksoud; Trad. Anna Maria Capovilla e José Ítalo Stelle. Brasília / São Paulo: Editora Universidade de Brasília / Visão, 1983 [1960]; HAYEK, F. A. Direito, Legislação e Liberdade: Uma Nova Formulação dos Princípios Liberais de Justiça e Economia Política. Apres. Henry Maksoud; Trad. Anna Maria Copovilla, José Ítalo Stelle, Manuel Paulo Ferreira e Maria Luiza X. de A. Borges. São Paulo: Visão, 1985. 3v. [1973 / 1976 / 1979]; HAYEK, F. A. Arrogância Fatal: Os Erros do Socialismo. Trad. Ana Maria Capovilla e Candido Mendes Prunes. Porto Alegre: Editora Ortiz / Instituto de Estudos Empresariais, 1995 [1988].
}

52 O autor é explicito sobre a importância da multidisciplinaridade: "Mas ninguém pode ser um grande economista se for somente um economista - e estou mesmo tentado a acrescentar que o economista que é somente um economista é provável que se torne um incômodo ou ainda um perigo positivo". HAYEK, F. A. The Dilemma of Specialization. In: Studies In Philosophy, Politics and Economics. p. 123.
As ordens espontâneas do segundo tipo, para o autor, são as únicas que possibilitam aumentos sustentados em seu grau de complexidade: o sistema de preços, a moeda, as línguas e as leis seriam exemplos de "frutos da ação, mas não da intenção humana"53. Esse grau progressivo de complexidade se torna possível porque nesse tipo de ordem existem mecanismos evolutivos de aprendizado, que tornam possível contornar os limites do conhecimento humano.

Hayek associa assim diferentes doutrinas políticas a diferentes pressupostos sobre a natureza desse conhecimento. Como na distinção popperiana entre racionalismo ingênuo e crítico, Hayek traça paralelo entre racionalismo construtivista e evolutivo. $\mathrm{O}$ primeiro, cartesiano, valoriza apenas aquilo que possa ser racionalmente reconstruído, gerando preferência por ordens baseadas em controle consciente (taxis). O segundo, marcado por um ceticismo inglês, cônscio das limitações do conhecimento formal para controlar ordens complexas, valoriza instituições descentralizadas, que permitem, além do conhecimento formal, o uso do conhecimento disperso dos agentes, ampliando assim drasticamente a quantidade de informação levada em conta pelos mecanismos coordenadores.

Estes últimos se desenvolveram por meio de um processo de evolução cultural de normas. Ex ante não é possível antecipar que tipo de ordem emerge quando os indivíduos seguem conjuntos específicos de normas. Mas, historicamente, a adoção de regras que levaram à prosperidade, como o respeito à propriedade privada, surgiu como fruto da experimentação de indivíduos em grupos que adotaram tais regras, sendo imitados pelos demais indivíduos que seguiam outros conjuntos de regras.

A liberdade individual como motor para um processo de descoberta que aumenta a

${ }^{53}$ HAYEK, F. A. The Results of Human Action but Not of Human Design. In: HAYEK, F. A. Studies in Philosophy, Politics and Economics. 
complexidade da ordem social tornou possível a existência de bilhões de pessoas interagindo com elevado grau de divisão do trabalho. Mas as instituições compatíveis com essa liberdade sofrem ataques, além daqueles desferidos pelo racionalismo construtivista, derivados dos instintos disfuncionais herdados do passado tribal da humanidade: a normas impessoais e abstratas que regulam as relações modernas geram estranhamento nas pessoas acostumadas com as regras adequadas para as relações em grupos menores, nos quais todos se conhecem. Dessa maneira, razão e instinto se rebelam contra a sociedade livre, dando origem ao totalitarismo. Depois de analisar o processo de evolução institucional e as ameaças coletivistas à sociedade livre, Hayek defende uma série de reformas institucionais concretas que pretendem livrar as pessoas dos monopólios impostos pelo estado.

A obra de Hayek inclui muito mais do que foi possível cobrir no espaço de um artigo. Nada falamos sobre suas propostas de política monetária no início da carreira, sua defesa da desnacionalização do dinheiro, sua tese da inexistência de liberdade política na ausência de liberdade econômica, suas teses sobre direito e propostas de reformas constitucionais, além de várias de suas teses filosóficas ou seus inúmeros trabalhos no campo da história das ideias. Todas elas, porém, seguem o padrão ditado pelo tema central que enfatizamos neste artigo.

Hayek nos legou não um conjunto de teorias definitivas e ferramentas prontas para serem usadas, mas a oportunidade de expandir o horizonte de questões cruciais que estão sem respostas até hoje. Por isso, Hayek exerce fascínio não entre aqueles que buscam o conforto em certezas, mas entre os curiosos, que não se distanciam de problemas intrincados. Sua macroeconomia convida a uma fundamentação não em modelos, mas em problemas microeconômicos, de modo que os profissionais da área não se preocupem apenas com agregados em detrimento de distorções em estruturas. A teoria do capital ainda aguarda formas de representar o aumento da complexidade das conexões entre seus elementos durante o processo de crescimento e sua distorção durante os ciclos. Sua teoria de processo aguarda ainda integração maior com fundamentação explícita na teoria evolucionária. Sua teoria institucional, da mesma maneira, requer que os diferentes mecanismos seletivos sejam explicitados em diferentes contextos, para que possamos avaliar melhor e guiar processos de transição institucional desejáveis.

Todos esses desafios são derivados da tensão essencial existente entre os elementos de complexidade e subjetivismo: como representar a complexidade sem minar o aspecto criativo da ação? Como falar em coordenação de planos sem levar em conta os fatores externos que limitam esses planos? A preferência deste revisor, pelo menos como primeiro passo, é claramente pelo referencial da epistemologia evolucionária, que une esses dois elementos em uma teoria de aprendizado, preferência essa consistente com os caminhos tomados nas obras de Hayek, em especial seu último livro, que adota explicitamente esse rumo.

Por fim, devemos observar que Hayek também nos legou um exemplo de integridade intelectual: nunca se furtou de examinar problemas intratáveis que considerasse fundamentais, sempre se ateve às suas convicções minoritárias, mesmo em prejuízo de sua carreira, nunca desrespeitou oponentes intelectuais ou procurou distorcer suas opiniões, nunca apelou para autopromoção, omitindo os esforços dos autores que abordaram os mesmos problemas antes dele, sempre se inteirou das diferentes opiniões sobre um assunto, mostrando erudição sobre tudo que se debruçava. Diante disso, somente o preconceito ideológico explica a falsa acusação de dogmatismo que periodicamente é lançada contra ele. cos 